\title{
This Is Just the Beginning
}

\author{
Climate Change, Positive Peace, and the \\ "New Normal"
}

\author{
Maxine Burkett and Naima Moore
}

The COVID-19 pandemic has upended daily life as we once knew it, and tested our capacity to respond effectively and "bounce forward" from catastrophe. Many have likened the pandemic to a trial run for the disastrous climate events to come. Some may believe that the end is nigh. What we are seeing, however, is just the beginning.

Reopening businesses and loosening restrictions may appear to be a cautious and protracted return to normal. However, from a climate perspective, "normal" was already a crisis - a time when climate crises were manifest throughout the islands and world. According to climate experts, this persistent state of crisis will continue as long as our leaders fail to drastically curb our emissions. While the pandemic-induced slowdown of industrialized economies has provided the world with a perceptible respite from pollution, our return to perceived normalcy should renew cause for concern.

As we embark on a new beginning, Hawai i's precarity in the face of nested crises in governance, disease, healthcare, and a rapidly changing climate underscores the critical need for financial, political, and social investment in resilient recovery - a recalibration of policy and economic models that prioritizes the needs of our communities and natural environment over offshore profits. Hawai' $i$ thus stands at a pivotal and promising embarkation point, one with the potential to determine our collective climate future and way of life for decades to come.

\section{Transformation through Peace, Peace through Transformation}

As opposed to depictions of collapse, we hold to visioning and effectuating "preferred futures." Hawai 'i's successful recovery from COVID-19 depends largely on cultivating "positive peace," which could lay the groundwork for strong, equitable, resilient communities. "Negative peace" describes only the absence of conflict. Positive peace is the measurable presence of attitudes, institutions, and systems that help humans flourish and prevent conflict from arising. When conflicts do arise, 
they are transformed to enhance cooperation and understanding, yielding ever stronger communities. The research is clear: as a community's positive peace increases - signaled by accountable governments, equitable economies, access to health care, and more ${ }^{1}$ - so too does its ability to mitigate emergent threats and protect vulnerable populations. Positive peace protects more lives and livelihoods exponentially.

The impacts of the climate crisis will vary across communities, as will the risks to peace and stability at the local level. We understand that when problems arise, local and sustainable solutions work best. Peacebuilding therefore requires and initiates a holistic approach to discerning the full ecosystem-human and non-human-in response to community needs. This is achieved through a protocol of ethical communication, listening first, and honoring and elevating community-based wisdom to guide us toward a just and sustainable future.

Hawai' $i$ is particularly well-situated to address peacebuilding in a time of emerging climate crisis and its convergence with such acute crises as COVID-19 and the movement to eradicate racial hierarchy and anti-black racism. Equidistant from populous and diverse countries and economies, the islands sit at the center of our Earth's climate crossroads and at the forefront of the perils - and possibilities that environmental change presents. Hawai' $i$ has fostered productive, place-based, and interdisciplinary climate policy endeavors. Though by no means free of racial hierarchy and discrimination, we have also forged a relative peace in culturally and ethnically diverse communities. Our rules of engagement differ from counterparts on the continent, suggesting greater possibility for healing and transformational change. Hawai' $i$ continues to pioneer in peacebuilding and peace education.

Along with other Pacific Island nations, Hawai'i's cultural legacy can provide a foundation for stronger policies that will protect the spiritual, reciprocal, and familial relationship between people and land, thereby enhancing human capital, right relations, and an equitable distribution of resources-all vital for positive peace. Hawai'i's state motto makes this explicit: "Ua mau ke ea o ka 'āina i ka pono," or "The life of the land is perpetuated in righteousness." Climate change not only threatens the physical environment, but also endangers an essential componentthe genealogical quintessence-of Native Hawaiian, Pacific Islander, and Aloha 'Âina cultural and spiritual identity, imperiling these communities' cultural legacies and the wellbeing of future Indigenous generations. As George Hu'eu Sanford Kanahele writes, "In the Hawaiian mind ... a sense of place [is] inseparably linked with self-identity and self-esteem. ... Being without a place ... mean[s] uprootedness in every sense of the word: being cut off from the most vital physical, psychological, social, and spiritual values of one's existence" $(175,182)$. Climate change is often discussed as impacting our material or economic health. However, it will have negative psychological impacts on communities that regard the land, seas, and mountains as members of their own family and genealogy. In pursuing lasting peace and resilience, Hawai'i's post-COVID rebuild must strive to preserve the 
identity and sense of wellbeing for our communities - and particularly our youth, who risk a short-changed life by living in a world completely altered in landscape and environmental quality.

\section{A Way Forward}

While COVID-19 and the climate crisis appear to signal societal collapse, these are fertile grounds for growth. Those in the Pacific facing threats to their lands through no fault of their own know all too well the consequences of inaction. To date, most Pacific nations have avoided COVID-19's decimating impact by shutting themselves off from the world. They can close their borders, but they cannot stem rising temperature and tides. Translating climate resilience and peacebuilding into tangible, culturally-responsive processes allows us to recover from this crisis, and to mitigate and prepare adequately for the next.

Food security is a potent example. Empty supermarket shelves and headlines about food and household and medical supplies raise serious concerns among government officials, healthcare providers, and residents about our extreme reliance on imported goods. Across the community, distinguishing between food security and food sovereignty has shifted from a marginal to a more central concern. Hawai 'i's near absolute dependence on external food sources maintains a perpetual state of instability and vulnerability. Small Island States with limited capacity for food production due to rising sea levels, lack of freshwater, and soil salinization are at the mercy of imports, which makes this concern even more poignant. Climate forecasts indicate that rising temperature and $\mathrm{CO} 2$ concentrations will make food more expensive and less nutritious - and with varying availability. Hawai' $i$, however, has great capacity for self-reliance in terms of food and nutritional security, which in turn would make us more resilient, and perhaps even a food source for our Pacific Island neighbors. Implementing policy that gives communities agency to grow and access locally-sourced food is just one way of promoting a sound business environment and ensuring equitable distribution of resources. This also promotes peace.

That Hawai' $i$ has one of the highest unemployment rates in the US due to COVID-19 also demonstrates a critical need for a more resilient economy that provides more economic equity (that preserves our peace) and durability (that protects our climate and our livelihoods). Several Hawai' i-based initiatives are working to achieve this, such as the 'Âina Aloha Economic Futures Declaration, dedicated to building a sustainable, pono economy based on Native Hawaiian cultural values, and the feminist economic recovery plan for Hawai' $i$, released by the Hawai' $i$ State Commission on the Status of Women, which advocates for a more sustainable and diverse economy. Indeed, Hawai' i's dependency on imports and lopsided fiscal reliance on tourism and the US military present an immediate roadblock to resiliency efforts. 
This moment of departure is an opportunity to usher in new, equitable, and regenerative communities, for which "normal" is defined by our resilience and cohesion in the face of change. Our islands cannot afford to revert back to the preCOVID normal: a state of being initiated by over a century of Western models of modernization (and globalization) and most recently defined by a creeping climate emergency. Creating pathways to a preferred future for our children and grandchildren simply requires that we take the first step.

\section{Note}

1. The eight pillars of peace are a well-functioning government, free flow of information, a sound business environment, acceptance of the rights of others, high levels of human capital, low levels of corruption, good relations with neighbors, and an equitable distribution of resources.

\section{Work Cited}

Kanahele, George Hu'eu Sanford. Kū Kanaka, Stand Tall: A Search for Hawaiian Values. U of Hawai'i P, 1993.

Maxine Burkett is the Co-Founder and Senior Advisor of the Institute for Climate and Peace, a Professor of Law at the University of Hawai'i, and a Global Fellow at the Wilson Center.

Naima Moore is an Intern at the Institute for Climate and Peace. 